\title{
Estimating microalgae Synechococcus nidulans daily biomass concentration using neuro-fuzzy network
}

\author{
Estimador neuro-fuzzy de concentração diária de biomassa da microalga Synechococcus nidulans
}

\author{
Vitor Badiale FURLONG ${ }^{1 \star}$, Renato Dutra PEREIRA FILHO ${ }^{1}$, Ana Cláudia MARGARITES ${ }^{1}$, \\ Pâmela Guder GOULARTE ${ }^{1}$, Jorge Alberto Vieira COSTA ${ }^{1}$
}

\begin{abstract}
In this study, a neuro-fuzzy estimator was developed for the estimation of biomass concentration of the microalgae Synechococcus nidulans from initial batch concentrations, aiming to predict daily productivity. Nine replica experiments were performed. The growth was monitored daily through the culture medium optic density and kept constant up to the end of the exponential phase. The network training followed a full $3^{3}$ factorial design, in which the factors were the number of days in the entry vector ( 3,5 and 7 days), number of clusters ( 10,30 and 50 clusters) and internal weight softening parameter (Sigma) $(0.30,0.45$ and 0.60$)$. These factors were confronted with the sum of the quadratic error in the validations. The validations had 24 (A) and 18 (B) days of culture growth. The validations demonstrated that in long-term experiments (Validation A) the use of a few clusters and high Sigma is necessary. However, in short-term experiments (Validation B), Sigma did not influence the result. The optimum point occurred within 3 days in the entry vector, 10 clusters and 0.60 Sigma and the mean determination coefficient was 0.95 . The neuro-fuzzy estimator proved a credible alternative to predict the microalgae growth.
\end{abstract}

Keywords: black-box; cellular concentration; predictive microbiology.

\section{Resumo}

Neste trabalho, foi construído um estimador neuro-fuzzy da concentração de biomassa da microalga Synechococcus nidulans a partir de concentrações iniciais da batelada, visando possibilitar a predição da produtividade. Nove experimentos em réplica foram realizados. O crescimento foi acompanhado diariamente pela transmitância do meio e mantido até o final da fase exponencial de crescimento. O treinamento das redes ocorreu segundo delineamento experimental $3^{3}$, os fatores foram o número de dias no vetor de entrada ( 3,5 e 7 dias), o número de clusters (10, 30 e 50 clusters) e o valor de abrandamento do filtro interno (Sigma) (0,30, 0,45 e 0,60). A variável resposta foi o somatório do erro quadrático das validações. Estas possuíam 24 (A) e 18 (B) dias de crescimento. As validações demonstraram que, em experimentos de longo período (Validação A), é necessário usar poucos clusters e Sigmas altos. Já, em curtos períodos (Validação B), o Sigma não gera alterações. O ponto ótimo ocorreu com 3 dias na entrada, com 10 clusters e Sigma de 0,60, cujo coeficiente de determinação médio foi 0,95. O estimador neuro-fuzzy mostrou-se uma alternativa robusta para predição do crescimento desta microalga.

Palavras-chave: black-box; concentração celular; microbiologia preditiva.

\section{Introduction}

Microalgae are widely studied due to their photosynthetic properties. Photosynthesis provides them with the ability to use carbon dioxide as carbon source, process known as dioxide biofixation, reducing $\mathrm{CO}_{2}$ emissions to the atmosphere (CHEN et al., 2009). Biofixation enables the microalgae to accumulate carbon, which promotes the synthesis of energy storage compounds. Among these compounds are micronutrients, carotenoids, vitamins and sterols, and macronutrients such as high biological value proteins, carbohydrates, and important fatty acids with 12-22 carbon atoms, often essentials, like liloneic and lilolenic acids (CHACÓN-LEE; GONZÁLEZ-MARINÕ, 2010).

The biomass obtained from the cultures may also be used in the production of second-generation biofuels, which are defined as those produced from non-alimentary biomass. Usually, second generation biofuels substrates are agriculture byproducts such as cereals straw, sugar cane bagasse, and generic effluents. Other substrates may also be generated biofuels production, such as modified gramineae, rapid growth forests and microalgae (SIMS et al., 2010).

Among these microalgae that may serve to the described purposes is the cyanobacteria Synechococcus nidulans. This species was identified over 30 years ago and is found in aquatic environments, mostly in well-lit surface water. Naturally occurring, Synechococcus biomass is generally abundant, with cellular densities that can vary from hundreds to millions of cells per milliliter of sea water (SIX et al., 2007).

In order to use microalgae full potential it is necessary to establish optimum culture parameters. This goal is accomplished by changing the nutritional and physical characteristics of the organism, as well as the configuration of the reactor.

Received 6/8/2012

Accepted 26/10/2012 (00B5825)

${ }^{1}$ Laboratory of Biochemical Engineering, School of Chemistry and Food Engineering, Federal University of Rio Grande - FURG, Rio Grande, RS, Brazil, e-mail: vitorfurlong@gmail.com

${ }^{*}$ Corresponding author 
Determination of kinetic factors and the employment of biomass concentration prediction are necessary to enable microalgae industrial scale utilization, which can be achieved by state estimators (ÇELEKLI; YAVUZATMACA, 2009).

Among the possible approaches that may be applied in the state estimator, the use of neuro-fuzzy networks is one that has gained attention in the scientific community. These networks are highly capable of dealing with nonlinearity and noise, which are inherent to bioprocesses (KHATAEE et al., 2011). A neuro-fuzzy network is an algorithm that processes information in a similar way the neuron structure in the human brain does. Each neuron in the first layer network is connected to the neurons in the second layer, as it is for the following layers, and is responsible for part of the knowledge diffused in the network (GADKAR; MEHRA; GOMES, 2005).

The way the network realizes its pattern recognition is similar to a classic mechanistic modeling. Data from the experiments are separated into two groups. The first group is the training group, which is used for the quadratic error minimization in order to compose the model. The error minimization in the neural network aggregates weights to each neuron connection that will be responsible by the output composition. When this stage is completed, the model is tested and is accomplished using the second group, the validation group. In the compose model or in neural network, this is evaluated by statistical tests (HU et al., 2008).

The fuzzy portion of the network is related to the fuzzy logic between the neurons. Fuzzy logic is an addendum to the Boolean logic, where an element may belong mutually to several groups, instead of one at a time, through a pertinence or membership function. It allows a more precise evaluation of how a variable may influence the final result (KARAKUZU; TÜCKER; ÖZTÜRK, 2006).

The neuro-fuzzy network is affected by internal or external factors. Concerning internal factors, the parameters involved may be the iteration quantity, weight softening parameters, internal digital filters, number of neuron layers or amount of neurons per layers, as well as how they connect. External factors such as vector size and form also affect the network. Changes in these parameters provide different responses outputted by the network model, thus calibrating such factors for a given data set generates higher robustness and assertiveness in the algorithm (TAYLOR, 2006).

However, neural networks are only sensitive to changes that occur within the training data. For instance, a trained network is capable of accurately predicting different profiles only if such data are obtained in the same manner as the training group. Any change in the data acquisition process, such as using different culture medium or reactor may change the data inner relations, rendering the network unable of returning a reliable output. To contemplate the process changes, it is possible to generate a new network-model by modifying the entry data, making the change a prediction parameter (MASTERS, 1995).

The amount of data required to the neuro-fuzzy network design is very large, thus it is necessary a computational system capable of performing these operations. SciLab is a software for numerical computation developed by INRIA (Institut National de Recherche en Informatique et en Automatique) and distributed under the GNU (General Public License). SciLab has several toolboxes for different tasks, including neural and neuro-fuzzy modules (SCHERER, 2010; BORDEIANU et al., 2008).

One available module is LOLIMOT (Local Linear Model Tree), a robust adaptive neuro-fuzzy system with learning capabilities, used for pattern recognition, system identification, image processing and prediction (MARZOOGHI et al., 2012). LOLIMOT is a Takagi-Sugeno-Kang (TKS) algorithm. This type of algorithm is employed in non-linear systems identification and presents advantages over other neural networks, such as smaller training sets and noise sensibility (MARSILI-LIBELLI, 2004).

Therefore, this study aimed to design a neuro-fuzzy state estimator for the estimation of daily concentration of Synechococcus nidulans using different initial batch profiles under nitrogen source restriction.

\section{Materials and methods}

\subsection{Microalgae culture}

Nine identical experiments were performed using the microalgae Synechococcus nidulans in Zarrouk medium (ZARROUK, 1966) with $50 \%$ of its original nitrogen source ( 1.25 g.L. $\mathrm{L}^{-1}$ of $\mathrm{NaNO}_{3}$ ). This species belongs to the Biochemical Engineering Laboratory collection, in the Federal University of Rio Grande. The cultures were prepared in closed 2L photobioreactors, under constant stirring using a diaphragm pump, sterile air at a flow of $0.480 \mathrm{~L} \cdot \mathrm{min}^{-1}$ and 2500 lux luminance with $12 \mathrm{~h}$ day/night photoperiod. The initial cellular concentration was 0.2 g. $\mathrm{L}^{-1}$.

\section{Cellular growth determination}

Cellular concentration was determinated each $24 \mathrm{~h}$ by measuring the absorbance of the culture medium in spectrophotometer at $670 \mathrm{~nm}$ (COSTA et al., 2002). The absorbance was then correlated with a previously established dry weight standard curve at the same wavelength. The cultures were kept under the experimental conditions until the end of the exponential growth phase. This period was established by three days of similar cellular concentrations, which demonstrated that the growth had ceased.

\subsection{Digital filter}

To correct the noise effects deriving from the large number of factors associated with microalgae growth, which may possess a negative effect on the repeatability and accuracy of the measurement, a noise reduction stage is necessary. To deal with these characteristics, a double exponential digital filter was employed. This utilizes a series of measurements $\left(\mathrm{x}_{n-1}, \mathrm{x}_{n}\right.$, $\left.\mathrm{x}_{n+1}, \ldots\right)$, and their corresponding filtered values $\left(\mathrm{y}_{n-1}, \mathrm{y}_{n}, \mathrm{y}_{n+1}\right.$, $\ldots$ ), where $n$ is the current sample value. The filter application follows Equation 1. 
$y_{n}=a^{2}+2 \times(1-a)-(1-a)^{2} \times y_{n-1}$

where $a$ is the internal softening parameter. As this parameter value approaches a unitary value, the output filtered value is closer to the unfiltered value. The established value for this study was 0.6 (SEBORG; EDGAR; MELLICHAMP, 1989).

\subsection{Numeric procedure}

The processing procedure used in the state estimator was establishing subsequent biomass concentrations with previous points. In order to generate more stable connections between the neurons, thus leveling different period experiments and improving processing abilities, the biomass concentration values were standardized between 0 and 1 by dividing all concentrations by the highest biomass concentration throughout the experiment.

An example of this procedure is feeding the system during the firsts three days as an entry vector in order estimate the culture growth. The response of the firsts three days was the fourth day. The fourth day biomass concentration data was then fed back into the input vector after excluding the first day, thus making the entry vector the second, third and fourth days. The response for this vector is the fifth daily biomass concentration. This procedure was repeated until the estimation reached the final experiment biomass concentration.

Therefore, during the network training it was necessary to provide to the algorithm all the biomass concentrations of the training group in the described fashion. This generated a matrix containing the entry concentration in the first three columns and the response in the last column. Hence, this group did not take part in the prediction, but it was responsible for composing the system's relations, enabling the prediction that was possible with another data set.

The validation group was used to determine the network performance and liability. To achieve the estimation, the initial days of the validation experiment was fed into the network in order to predict the following concentration in the described manner. Such fashion was repeated until the complete culture profile was estimated.

\subsection{Topology optimization}

For assigning the correct architecture to the neuro-fuzzy network, a wide variety of design alternatives must be evaluated. Therefore, an experimental design may be applied to diminish and generate simpler array of essays. In this study, a full $3^{3}$ factorial design was applied to the neuro-fuzzy network, whose parameters were: number of the days in the entry vector, number of clusters and the internal weight softening parameter ( $\sigma$, Sigma).

Changing the number of concentration points during the training and network utilization the number of days in the entry vector varied. Architectures were constructed with 3, 5 and 7 days in the entry vector.
Clustering are the iteration manner in which the network minimizes the error between the data and the composed model; as more clusters are added into the network more the error value decreases. However, when adding clusters beyond the necessary value, the algorithm becomes narrow and is only capable of running with data similar to the training universe, thus loses robustness. This phenomenon is known as overtraining (MASTERS, 1995). In this study, 10, 30 and 50 clusters were evaluated.

The internal weight softening parameter $(\sigma$, Sigma) is part of a digital filter, which is accountable for how the algorithm is affected by the noise in the entry data. As a factor in the experimental design, Sigma was evaluated in the levels 0.30 , 0.45 and 0.60 .

The dependent variable used in the experimental design was the Sum of Quadratic Error (SQE) between the validation of biomass concentration values of the present experiment and the biomass concentration estimated by the network.

The experimental design was performed using the statistical software $\mathrm{R}$. $\mathrm{R}$ is a programming language and software environment for statistical computing and graphics freely available under the GNU license. The design was realized in a calculation package of R named "RcmdrPlugin.DoE", which is a GUI (Graphical User Interface) for the R console (GRÖMPING, 2011)

\section{Results and discussion}

The 9 experiments resulted in 14 to 24 days of culture growth and maximum biomass concentration of 1.28 g. $\mathrm{L}^{-1}$. Two experiments were randomly selected to be used in the validation group: Validation A with 24 days of culture growth and Validation B with 18 days of culture growth. The daily experiments of biomass concentration are presented in Table 1.

For the training experiments, 27 networks were used to complete the experimental design. Each network was then evaluated using both validation experiments. The estimation profiles with the least sum of quadratic errors for each entry vector of both validations are presented in Figure 1.

Table 2 presents a summary of the experimental design, where only the effects and conjugated parameters that were significant at a $90 \%$ confidence level are displayed.

The results show that Validation A (24 days) presented significant parameters for the factors interactions and the linear factors of clusters and Sigma. The linear Sigma effect presented a negative value and the linear cluster effect had a positive effect, being the response variable the sum of quadratic error. Negative effects denote an improvement in the network prediction capability. Validation A demonstrated that for longterm experiments the number of days did not influence the final result, enabling the use of a small entry vector. However, it is necessary to decrease the number of clusters, as well as increase the internal filter influence in order to counterbalance the lack of iterations and the small amount of entry data in which the 
Table 1. Biomass Concentrations in the Experiments.

\begin{tabular}{|c|c|c|c|c|c|c|c|c|c|}
\hline \multirow{2}{*}{ Time (d) } & \multicolumn{7}{|c|}{ Training experiments (g.L $\left.\mathrm{L}^{-1}\right)$} & \multicolumn{2}{|c|}{ Validation experiments (g. $\left.\mathrm{L}^{-1}\right)$} \\
\hline & 1 & 2 & 3 & 4 & 5 & 6 & 7 & 24 Days & 18 Days \\
\hline 1 & 0.20 & 0.22 & 0.20 & 0.21 & 0.21 & 0.22 & 0.21 & 0.22 & 0.22 \\
\hline 2 & 0.26 & 0.26 & 0.32 & 0.32 & 0.30 & 0.27 & 0.29 & 0.30 & 0.29 \\
\hline 3 & 0.28 & 0.27 & 0.34 & 0.35 & 0.33 & 0.35 & 0.34 & 0.31 & 0.36 \\
\hline 4 & 0.31 & 0.28 & 0.36 & 0.36 & 0.35 & 0.42 & 0.40 & 0.32 & 0.42 \\
\hline 5 & 0.34 & 0.29 & 0.38 & 0.38 & 0.36 & 0.50 & 0.49 & 0.32 & 0.49 \\
\hline 6 & 0.38 & 0.30 & 0.42 & 0.43 & 0.40 & 0.54 & 0.57 & 0.33 & 0.52 \\
\hline 7 & 0.41 & 0.31 & 0.45 & 0.49 & 0.41 & 0.57 & 0.64 & 0.35 & 0.56 \\
\hline 8 & 0.45 & 0.33 & 0.47 & 0.55 & 0.41 & 0.60 & 0.68 & 0.36 & 0.59 \\
\hline 9 & 0.49 & 0.42 & 0.49 & 0.57 & 0.42 & 0.64 & 0.73 & 0.40 & 0.64 \\
\hline 10 & 0.51 & 0.48 & 0.52 & 0.58 & 0.44 & 0.67 & 0.81 & 0.42 & 0.69 \\
\hline 11 & 0.52 & 0.63 & 0.53 & 0.58 & 0.45 & 0.74 & 0.86 & 0.47 & 0.74 \\
\hline 12 & 0.52 & 0.68 & 0.55 & 0.63 & 0.46 & 0.79 & 0.86 & 0.50 & 0.79 \\
\hline 13 & 0.53 & 0.74 & 0.59 & 0.70 & 0.47 & 0.83 & 0.86 & 0.52 & 0.83 \\
\hline 14 & 0.56 & 0.75 & 0.61 & 0.71 & 0.48 & 0.80 & 0.86 & 0.54 & 0.95 \\
\hline 15 & 0.60 & 0.85 & 0.59 & 0.73 & 0.49 & 0.77 & & 0.63 & 1.01 \\
\hline 16 & 0.62 & 0.88 & 0.58 & 0.77 & 0.46 & 0.75 & & 0.70 & 1.05 \\
\hline 17 & 0.70 & 0.95 & 0.56 & 0.81 & 0.45 & & & 0.75 & 1.06 \\
\hline 18 & 0.74 & 1.00 & & & & & & 0.77 & 1.06 \\
\hline 19 & 0.76 & 1.07 & & & & & & 0.79 & \\
\hline 20 & 0.78 & 1.19 & & & & & & 0.82 & \\
\hline 21 & 0.84 & 1.28 & & & & & & 0.83 & \\
\hline 22 & 0.97 & & & & & & & 0.92 & \\
\hline 23 & 0.97 & & & & & & & 0.97 & \\
\hline 24 & 1.01 & & & & & & & 1.02 & \\
\hline
\end{tabular}

(a)
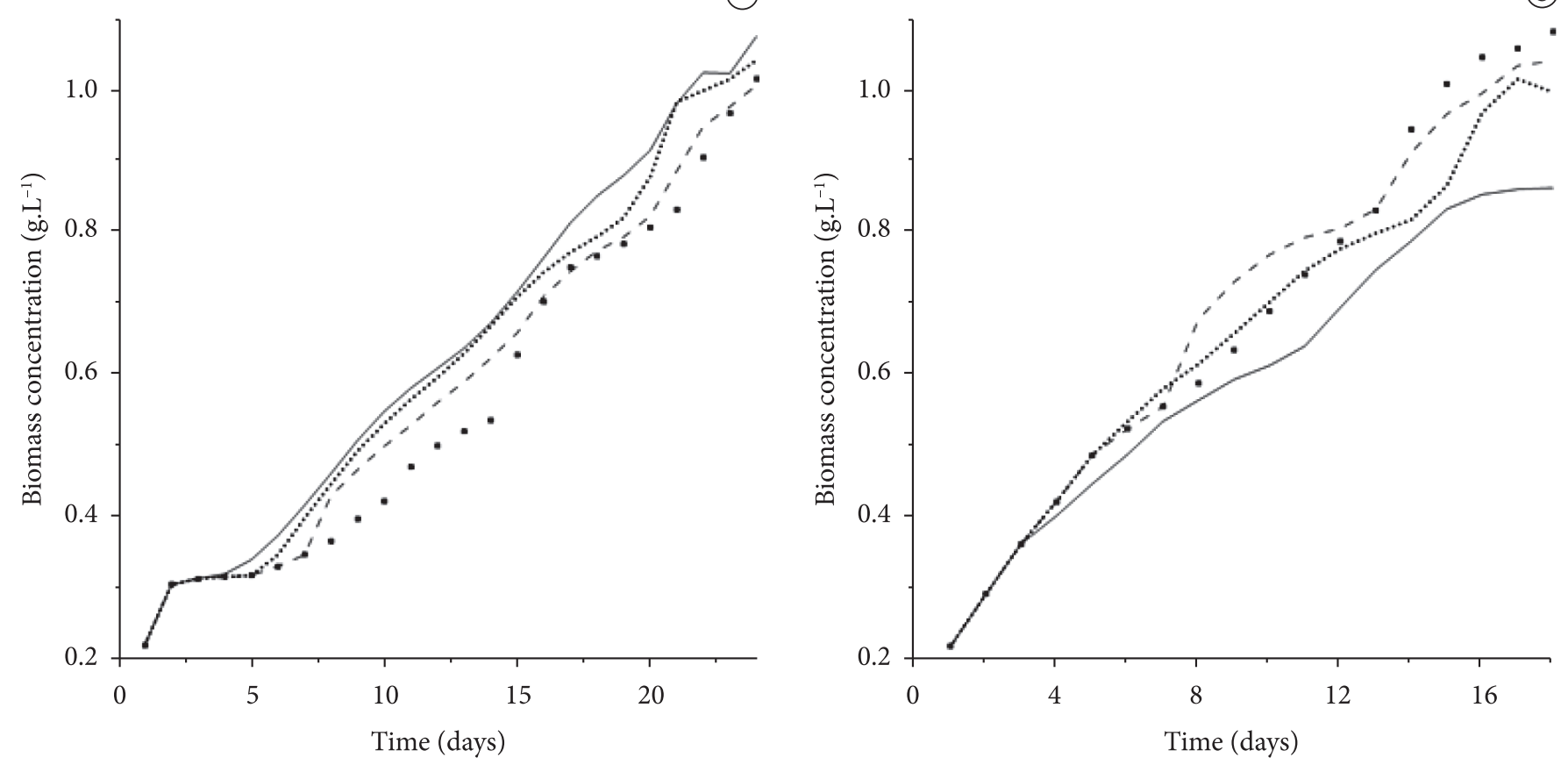

Figure 1. Biomass Prediction Profiles. (a) Validation with 24 days: ( $)$ ) Experimental Data, (-) 50 Clusters, Sigma 0.60, 3 Entry Vector, (‥) 10 Clusters, Sigma 0.60, 5 Entry Vector (---)10 Clusters, Sigma 0.60, 7 Entry Vector; (b) Validation with 14 Days, ( $\mathbf{a})$ Experimental Data, (-) 30 Clusters, Sigma 0.45, 3 Entry Vector; (‥) 10 Clusters, Sigma 0.60, 5 Entry Vector (---)10 Clusters, Sigma 0.60, 7 Entry Vector. 
pattern recognition can be realized. This is supported by the fact that in Validation A, a network that used 3 days in the entry vector, 10 clusters and Sigma 0.60 reached the sum of quadratic error approximately half the essays with the same number of clusters and entry vector.

To perform further analysis of the experimental design is necessary to discuss the model generated by the design and its coupled response surface. Nevertheless, the calculated Fisher F-value for the regression (1.021) was smaller than the standard (2.040) for this situation (18 degrees of freedom for residual and 8 for regression); thus, this model is not predictive, precluding the model and response surface analysis.

Validation B (18 Days) otherwise presented significant parameters for the interaction, the linear cluster and days in the entry vector effects, the interactions between linear Sigma and linear clusters, linear Sigma and days in the entry vector in its quadratic portion and linear clusters and quadratic days

Table 2. Full $3^{3}$ Factorial Design Summary.

\begin{tabular}{clrrrc}
\hline Validation & Parameter & $\begin{array}{c}\text { Estimated } \\
\text { effect }\end{array}$ & $\begin{array}{c}\text { Standard } \\
\text { error }\end{array}$ & T value & $\begin{array}{c}\text { Regression } \\
\text { coefficient }\end{array}$ \\
\hline \multirow{2}{*}{ A } & Intercept & 1.857 & 0.366 & 5.075 & 1.857 \\
& Sigma (L) & -1.265 & 0.634 & -1.996 & -0.632 \\
& Cluster (L) & 1.199 & 0.634 & 1.891 & 0.599 \\
B & Intercept & 2.262 & 0.422 & 5.36 & 2.262 \\
& Cluster (L) & 2.809 & 0.731 & 3.843 & 1.405 \\
& Days (L) & 1.630 & 0.731 & 2.229 & 0.815 \\
& Sigma (L): & 2.724 & 1.266 & 2.151 & 1.365 \\
& Cluster (L) & & & & \\
& Sigma (L): & -3.093 & 1.266 & -2.443 & -1.546 \\
& Days (Q) & & & & \\
& Cluster (L): & -3.604 & 1.266 & -2.845 & -1.801 \\
& Days (Q) & & & & \\
\hline
\end{tabular}

Validation A: 24 days experiment; Validation B: 18 days experiment. (L) Linear Effect; (Q) Quadratic Effect. portion. The calculated Fisher F-value for the regression (2.883) was larger than the standard (2.040); therefore, the response surface model generation process is possible. The coded model for this design is presented in Equation 2:

$S Q E=2.26+1.40 \times C+0.81 \times D-1.36 \times S \times C$
$-1.54 \times S \times D^{2}-1.80 \times C \times D^{2}$

where $C$ is the number of clusters, $D$ is the number of days in the entry vector and $S$ is the internal weight softening parameter. Since the presented model poses three coefficients to enable the graphical representation, the postulation of a given parameter is needed. Given that the Sigma parameter, alone, had no influence in interaction with other variables, at this confidence level it was determined that this value would be established in the experimental design in order to construct the response surfaces of the adjacent parameters. The responses surfaces are presented in Figure 2.

Despite the profiles changes according to each Sigma factor, the surfaces analysis establishes that lower values of quadratic error are achieved primarily in small entry vector, and, as the Sigma increases, in larger number of clusters. The smallest quadratic error was found in the experiment within 3 days in the entry vector, 0.45 Sigma and 10 clusters, in agreement with the surface and effects found in short-term experiments.

Consequently, in order to contemplate both experiment periods, the number of clusters must be small, 10 clusters, since the architecture was improved in both validations. The second parameter is the use of a small entry vector, 3 days, as it did not influenced the long-term culture validation and improved the network performance in the short-term experiment. The last parameter is the use of a large Sigma factor $(0.60)$ as it improves assertion in long-term experiments and does not influence greatly brief cultures prediction. Also the relatively large Sigma factor improves the network robustness even in the presence of large noise variance. In this situation, the mean determination coefficient $\left(R^{2}\right)$ between the present experiment data and the estimated biomass concentrations was 0.95 for both validations.
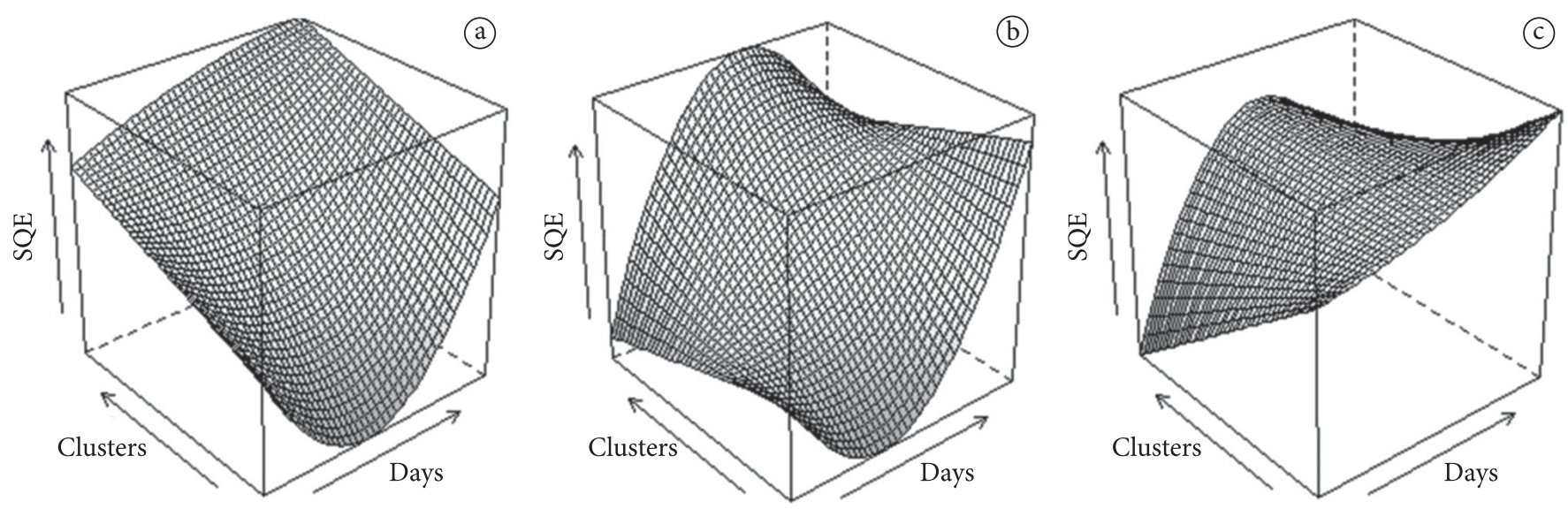

Figure 2. Response Surfaces for Sum of Quadratic Error with Postulated Sigma. (a) Response Surface at Sigma 0.30; (b) Response Surface at Sigma 0.45; (c) Response Surface at Sigma 0.60. 


\section{Conclusion}

The neuro-fuzzy estimator architecture is more reliable and generates better estimated profiles when three initial biomass concentrations are used in the entry vector. The network used 10 clusters iterations under an internal weight softening parameter of 0.60 . With this architecture, the network accomplished estimated profiles with a mean determinatison coefficient of 0.95 in relation to the present biomass concentration data.

Thus, the estimator composed in the present study is a viable alternative tool to estimate future biomass concentration of microalgae, such as Synechococcus nidulans, from initial batch growth data, enabling a more extensive control over the autotrophic bioprocess and an optimization in generating biomass.

\section{Acknowledgements}

The authors would like to thank Nanofotobiotec Network supported by CAPES for sponsoring the equipments, as well as undergraduate and doctorate scholarships.

We also would like to thank the INRIA research group, especially Yann Collete, author of the LOLIMOT package, as well as the R Project contributors and the entire Open Source community for providing its knowledge and dedication to other peers.

\section{References}

BORDEIANU, C. C. et al. Scilab software package for the study of dynamical systems. Computational Physics Community, v. 178, n. 10, p. 788-793, 2008. http://dx.doi.org/10.1016/j.cpc.2008.01.002

ÇELEKLI, A.; YAVUZATMACA, M. Predictive modeling of biomass production by Spirulina platensis as a function of nitrate and NACL concentrations. Bioresource technology, v. 100, n. 4, p. 1847-1851, 2009. PMid:18993057. http://dx.doi.org/10.1016/j. biortech.2008.09.042

CHACÓN-LEE, T. L.; GANZÁLEZ-MARINÕ, G. E. Microalgae for "healthy" food-possibilities and challenges. Comprehensive Reviews in Food Science and Food Safety, v. 9, n. 1, p. 655-675, 2010. http://dx.doi.org/10.1111/j.1541-4337.2010.00132.x

CHEN, P. et al. Review of the biological and engineering aspects of algae to fuels approach. International Journal of Agriculture and Biochemical Engineering, v. 2, n. 1, p. 1-30, 2009.

COSTA, J. A. V. et al. Modeling of Spirulina platensis growth in fresh water using resonse surface methodology. World Journal of Microbiology and Biotechnology, v. 18, n. 7, p. 603-607, 2002. http://dx.doi.org/10.1023/A:1016822717583
GADKAR, K. G.; MEHRA, S.; GOMES, J. On-line adaptation of neural network for bioprocess control. Computers and Chemical Engineering, v. 29, p. 1047-1057, 2005. http://dx.doi.org/10.1016/j. compchemeng.2004.11.004

GRÖMPING, U. Tutorial for Designing Experiments Using R Package RcmdrPlugin.DoE. Berlin: Fachbereich Ii Beuth Hochschule Für Technik Berlin, 2011. 54 p.

HU, D. et al. The design and optimization for light-algal bioreactor controller based on artificial neural network-model predictive control. Acta Astronautica, v. 63, p. 1067-1075, 2008. http://dx.doi. org/10.1016/j.actaastro.2008.02.008

KARAKUZU, C.; TÜKER, M.; ÖZTÜRK, S. Modelling, online state estimation and fuzzy control of production scale fed-batch baker's yeast fermentation. Control Engineering Practice, v. 14, p. 959-974, 2006. http://dx.doi.org/10.1016/j. conengprac.2005.05.007

KHATAEE, A.R. et al. Neural network modeling of biotreatment of triphenylmethane dye solution by a green macroalgae. Chemical Engineering Research And Design, v. 89, p. 172-178, 2011. http:// dx.doi.org/10.1016/j.cherd.2010.05.009

MARSILI-LIBELLI, S. Fuzzy prediction of the algal blooms in Orbetello lagoon. Enviromental Modeling \& Software, v. 19, p. 799-808, 2004. http://dx.doi.org/10.1016/j.envsoft.2003.03.008

MARZOOGHI, H. et al. Dynamic modeling of solid oxide fuel cell stack based on local linear model tree algorithm. International Journal of Hydrology Engineering, v. 37, n.1, p. 4367-4376, 2012. http://dx.doi.org/10.1016/j.ijhydene.2011.11.149

MASTERS, T. Advanced Algorithms for Neural Networks - A C++ Sourcebook. 2nd ed. New York: John Wiley \& Sons Inc., 1995. 430 p.

SCHERER, C. Métodos Computacionais da Física. São Paulo: Editora Livraria Da Física, 2010. 358 p.

SEBORG, D. E.; EDGAR, T. F; MELLICHAMP, D. A. Process Dynamics and Control. New York: John Wiley \& Sons Inc., 1989. 700 p.

SIMS, R. E. H. et al. An overview of second generation biofuels technologies. Bioresource Technology, v. 101, n. 1, p. 1570-1580, 2010. PMid:19963372. http://dx.doi.org/10.1016/j. biortech.2009.11.046

SIX, C. et al. Diversity and evolution of phycobilisomes in marine Synechococcus spp.: a comparative genomics study. Genetic Biology, v. 8, p. R259, 2007. PMid:18062815 PMCid:2246261. http://dx.doi. org/10.1186/gb-2007-8-12-r259

TAYLOR, B. J. Methods and Procedures for Verification and Validation of Artificial Neural Networks. New York, United States of America: Springer Science; Business Media Inc., 2006. 277 p.

ZARROUK, C. Contribuition à Iétude dune Cyanophycée: influence de divers facteurs physiques et chimiques sur la croissance et la photosynthèse de spirulina máxima. 1966. Tese (Doctorat)Université Des Paris, Paris, 1966. 